\title{
Removal of Phenol and Lead from Synthetic Wastewater by Adsorption onto Granular Activated Carbon in Fixed Bed Adsorbers: predication of Breakthrough Curves
}

\author{
A. H. Sulaymon', D. W. Abood ${ }^{2}$, A. H. Ali* \\ ${ }^{1}$ Environmental Engineering Department, University of Baghdad, Baghdad, Iraq \\ ${ }^{2}$ Environmental Engineering Department, University of Al-Mustansirria, Bagdad, Iraq
}

\begin{abstract}
The adsorption of phenol and lead (II) onto granular activated carbon (GAC) in single and binary system has been studied using fixed bed adsorber. A general rate multi-component model has been utilized to predict the fixed bed breakthrough curves for dual-component system. This model considers both external and internal mass transfer resistances as well as axial dispersion with non-liner multi-component isotherm. The effect of important parameter,such as flow rate, bed height and initial concentration on the behavior of breakthrough curves have been studied. The equilibrium isotherm Model parameters such as isotherm model constants, pore diffusion coefficients $\left(D_{p}\right)$ were obtained from batch experiments, while the external mass transfer coefficients and axial dispersion $\left(k_{f}, D_{z}\right)$ were calculated from empirical correlations. The results shows that the general rate model was found suitable for describing the adsorption process of the dynamic behavior of the GAC adsorber column.
\end{abstract}

\section{Keywords: Adsorption; GAC; phenol; lead; Fixed bed}

Nomenclature: b: Adsorption equilibrium constant relate to affinity between adsorbent and adsorbate, $\mathrm{m}^{3} / \mathrm{kg}$; Bi: Biot number; C: Fluid phase concentration, $\mathrm{kg} / \mathrm{m}^{3} ; \mathrm{C}_{\mathrm{e}}$ : Equilibrium liquid phase concentration, $\mathrm{kg} / \mathrm{m}^{3} ; \mathrm{C}_{\mathrm{o}}$ : Initial liquid phase concentration, $\mathrm{kg} / \mathrm{m}^{3} ; \mathrm{D}_{\mathrm{z}}$ : Axial dispersion coefficient; $\mathrm{m}^{2} / \mathrm{s}: \mathrm{D}_{\mathrm{m}}$ Molecular diffusivity, $\mathrm{m}^{2} / \mathrm{s} ; \mathrm{D}_{\mathrm{p}}$ : Pore diffusion coefficient, $\mathrm{m}^{2} / \mathrm{s} ; \mathrm{d}_{\mathrm{p}}$ : Particle diameter, $\mathrm{mk}_{\mathrm{f}}$ : MW: External mass transfer coefficient, $\mathrm{m} / \mathrm{s}$; Molecular weight, $\mathrm{g} / \mathrm{mol}$; L: Length of the column, m; Pe: Peclet number; $\mathrm{q}_{e}$ : Adorption capacity at equilibrium, $\mathrm{kg} / \mathrm{kg} ; \mathrm{q}_{\mathrm{m}}$ : Langmuir constant related to maximum adsorption capacity, kg/kg; r: Radial coordinate, m; R: Radial coordinate, m; Re: Renold number, $R e=\rho_{w} v d_{p} / \mu_{w} ; R_{p}$ : Radius of particle, $m ; S c$ : Schmidt number, $\mathrm{Sc}=\mu_{\mathrm{w}} / \rho_{\mathrm{w}} \mathrm{D}_{\mathrm{m}}$; Sh: Sherwood number, $\mathrm{Sh}=\mathrm{k}_{\mathrm{f}} \mathrm{d}_{\mathrm{p}} / \mathrm{D}_{\mathrm{m}} ; \mathrm{t}$ : Time, $\mathrm{s} ; \mathrm{V}$ : Volume of solution, $\mathrm{m}^{3} ; \mathrm{W}_{\mathrm{A}}$ : Mass of granular activated carbon, $\mathrm{kg} ; \mathrm{Z}$ : Axial distance, $\mathrm{m} ; \varepsilon_{\mathrm{b}}$ : Bed porosity; $\varepsilon_{\mathrm{p}}: \mu_{\mathrm{w}}$ Particle porosity; Viscosity of water; $v$ : Interstitial velocity, $v=\mathrm{Q} / \pi \mathrm{R}^{2} \varepsilon_{\mathrm{b}} ; \rho_{\mathrm{w}}$ : Density of water, $\mathrm{kg} / \mathrm{m}^{3}$; $\rho_{\mathrm{p}}$ : Particle densty, $\mathrm{kg} / \mathrm{m}^{3}$; Subscript b: Bulk fluid phase; e: equilibrium; GAC: Granular Activated Carbon; i: Component number, 1,2,..; L: Liquid Phase; o: Initial phase; p: Particle phase; Ph: Phenol; $\mathrm{Pb}^{+2}$ : Lead

\section{Introduction}

The removal of toxic contaminants such as heavy metal ions and organic pollutants from industrial wastewaters is one of the most important environmental issues to be solved today. Lead (II) has been found together with a variety of aromatic compounds including phenol, naphthalene, and trichloroethylene (TCE) at high concentrations in a number of contaminated sites. Lead (II) and its organic co-pollutants often originate from industrial sources such as the iron-steel, cook, petroleum, pesticides, paints, solvent, pharmacuities, wood preserving chemicals. Phenol containing water, when chlorinated during disinfection of water results in the formation of chlorophenol [1-3].

Adsorption is a well-established and powerful technique for treating domestic and industrial effluents. Activated carbon is the most widely and effectively used adsorbent. A typical activated carbon particle, whether in a powdered or granular form, has a porous structure consisting of a network of interconnected macropores, mesopores, and micropores that provide a good capacity for the adsorption of organic molecules due to high surface area. The surface chemistry of activated carbon and the chemical characteristics of adsorbate, such as polarity, ionic nature, functional groups, and solubility, determine the nature of bonding mechanisms as well as the extent and strength of adsorption. A variety of physicochemical mechanisms/forces, such as van der Waals, H-binding, dipole dipole interactions, ion exchange, covalent bonding, cation bridging, and water bridging, can be responsible for the adsorption of organic compounds in activated carbon [4-6].

While much research has been carried out on the uptake of single species of metal ions and organic species by activated carbon, little attention seems to have been given to the study of organic-metal ion mixtures. Despite the fact that not only single toxic metallic species but organic components also exist in wastewaters and the presence of a multiplicity of metals and organics often gives rise to interactive effects, insufficient attention seems to have been paid to this problem. The examining the effects of metal ions and organics in various combinations is more representative, of the actual environmental problems faced by treatment technologies, than are single metal or organic studies [7-11].

Fixed bed adsorber is the most efficient arrangement for conducting adsorption process for industrial applications in wastewater treatment [12]. The design of an adsorption column depends on various important parameters such as flow rate, initial concentration and bed height (mass of adsorbent). Understanding of adsorption characteristics, determination of break point time for adsorption operation and

*Correspondingauthor:A.H.Ali,EnvironmentalEngineeringDepartment,University of Al-Mustansirria, Bagdad, Iraq, E-mail: ahmedhassoon_2021@yahoo.com

Received June 18, 2011; Accepted August 25, 2011; Published August 31, 2011

Citation: Sulaymon AH, Abood DW, Ali AH (2011) Removal of Phenol and Lead from Synthetic Wastewater by Adsorption onto Granular Activated Carbon in Fixed Bed Adsorbers: predication of Breakthrough Curves. Hydrol Current Res 2:120. doi:10.4172/2157-7587.1000120

Copyright: (c) 2011 Sulaymon $\mathrm{AH}$, et al. This is an open-access article distributed under the terms of the Creative Commons Attribution License, which permits unrestricted use, distribution, and reproduction in any medium, provided the original author and source are credited. 
effective utilization of the column is possible by carrying out the mathematical modeling of fixed-bed adsorption column. Continuous adsorption studies are required to collect the experimental data for the design of adsorption column and for subsequent scale-up from pilot plant to industrial scale operation. There are several mathematical models in the literature, which have been used to represent the dynamic of the fixed bed column. Models with analytical solutions are often used to represent for fitting the breakthrough curve. These models which are available, exclude some of the important physical aspects such as axial dispersion and intra-particle resistances along the bed length and linear isotherm. However, these models applied only for mono-component system [13-17].

In the present study; as a new application onto our previous work, a general multi-component model is used to predict the breakthrough curves in fixed bed column for binary component for organic and inorganic pollutants onto GAC and compare the experimental results with that simulated by numerical solution of model which includes film mass transfer, pore diffusion resistance, axial dispersion and nonliner isotherm $[18,19]$.

\section{Mathematical Modeling and Simulation}

In the present study, a mathematical model for the fixed-bed column is proposed by incorporation of an important parameter, external mass transfer, resistance, internal mass transfer resistance and non-liner multi-component isotherm. The proposed model can be extensively used for understanding the dynamics of fixed-bed adsorption column for the adsorption of organic and inorganic (metal ions) compounds. To formulate a generalized model for the fixed-bed adsorption column, following assumptions are made [20]

- Equilibrium of adsorption is described by the nonlinear multicomponent Langmuir isotherm.

- Mass transfer across the boundary layer surrounding the solid particles is characterized by external-film mass transfer coefficient $\left(\mathrm{k}_{\mathrm{f}}\right)$.

- Intra-particle mass transfer is characterized by pore diffusion coefficient $\left(\mathrm{D}_{\mathrm{p}}\right)$

- Macro-porous adsorbent particles are spherical and homogeneous in size and density.

- Compressibility of the mobile phase is negligible.

- Fluid inside particles (macropores) is stagnant, i.e., there is no convective flow inside macropores.

- The adsorption process is isothermal. There is no temperature change during a run.

- The concentration gradients in the radial direction are negligible.

- All mechanisms which contribute to axial mixing are lumped together into a single axial dispersion coefficient.

Based on the assumption of the model, the governing equations for multi-component system can be obtained from differential mass balance of the bulk-fluid phase and the particles phase respectively:

Continuity equation in the bulk -fluid phase :

$$
-D_{z i} \frac{\partial^{2} C_{b i}}{\partial Z^{2}}+V_{i} \frac{\partial C_{b i}}{\partial Z}+\frac{\partial C_{b i}}{\partial t}+\frac{3 k_{f i}\left(1-\varepsilon_{b}\right)}{\varepsilon_{b} R_{p}}\left[C_{b i}-C_{p i, R=R_{p}}\right]=0
$$

Continuity equation inside the particle phase :

$$
\left(1-\varepsilon_{p}\right) \frac{\partial C_{p i}^{*}}{\partial t}+\varepsilon_{p} \frac{\partial C_{p i}}{\partial t}-\varepsilon_{p} D_{p i}\left[\frac{1}{R_{p}^{2}} \frac{\partial}{\partial R_{p}}\left(R_{p}^{2} \frac{\partial C_{p i}}{\partial R_{p}}\right)\right]=0
$$

Initial and boundary conditions:

The initial and boundary conditions may be represented by the following equations:

Initial Condition $(t=0)$ :

$$
\begin{aligned}
& C_{b i}=C_{b i}(0, Z)=0 \\
& C_{p i}=C_{p i}(0, R, Z)=0
\end{aligned}
$$

Boundary Conditions:

$$
\begin{aligned}
& Z=0: \frac{\partial C_{b i}}{\partial Z}=\frac{v}{D_{b i}}\left(C_{b i}-C_{o i}\right) \\
& Z=L: \quad \frac{\partial C_{b i}}{\partial Z}=0 \\
& R=0: \frac{\partial C_{p i}}{\partial R}=0 \\
& R=R_{p}: \frac{\partial C_{p i}}{\partial R}=\frac{k_{f i}}{\varepsilon_{p} D_{p i}}\left(C_{b i}-C_{p i, R=R_{p}}\right)
\end{aligned}
$$

Dimensionless Groups:

Defining the following dimensionless variables:

$c_{b i}=\frac{C_{b i}}{C_{o i}}, c_{p i}=\frac{C_{p i}}{C_{o i}}, c_{p i}^{*}=\frac{C_{p i}^{*}}{C_{o i}}, \tau=\frac{v t}{L}, r=\frac{R}{R_{p}}, z=\frac{Z}{L}$

Also, the dimensionless parameters are defining as:

$$
P e_{i}=\frac{v L}{D_{z i}}, B i_{i}=\frac{k_{f i} R_{p}}{\varepsilon_{p} D_{p i}}, \eta_{i}=\frac{\varepsilon_{p} D_{p i} L}{R_{p}^{2} v}, \zeta_{i}=\frac{3 B i_{i} \eta_{i}\left(1-\varepsilon_{b}\right)}{\varepsilon_{b}}
$$

The model equations can be transformed into the following dimensionless equations:

$$
\begin{aligned}
& -\frac{1}{P e_{i}} \frac{\partial^{2} c_{b i}}{\partial z^{2}}+\frac{\partial c_{b i}}{\partial z}+\frac{\partial c_{b i}}{\partial \tau}+\zeta_{i}\left(c_{b i}-c_{p i, r=1}\right)=0 \\
& \frac{\partial}{\partial \tau}\left[\left(1-\varepsilon_{p}\right) c_{p i}^{*}+\varepsilon_{p} c_{p i}\right]-\eta_{i}\left[\frac{1}{r^{2}} \frac{\partial}{\partial r}\left(r^{2} \frac{\partial c_{p i}}{\partial r}\right)\right]=0
\end{aligned}
$$

In these equations, the Peclet number $\left(P e_{i}\right)$ reflects the ratio of the convection rate to the dispersion rate, while the Biot number $\left(B i_{i}\right)$ reflects the ratio of the external film mass transfer rate to the intraparticle diffusion rate.

Initial conditions become $(\tau=0)[21,22]$ :

$$
\begin{aligned}
& c_{b i}=c_{b i}(0, z)=0 \\
& c_{p i}=c_{p i}(0, r, z)=0
\end{aligned}
$$

And boundary conditions become;

$$
\mathrm{z}=0: \frac{\partial c_{b i}}{\partial z}=P e_{i}\left(c_{b i}-1\right)
$$




$$
\begin{aligned}
& \mathrm{z}=1: \quad \frac{\partial c_{b i}}{\partial z}=0 \\
& \mathrm{r}=0: \quad \frac{\partial c_{p i}}{\partial r}=0 \\
& \mathrm{r}=1: \frac{\partial c_{p i}}{\partial r}=B i_{i}\left(c_{b i}-c_{p i, r=1}\right)
\end{aligned}
$$

The concentration $c_{\mathrm{pi}}^{*}$ in equation (10) is the dimensionless concentration of component $i$ in the solid phase of the particles. It is directly linked to a multi-component isotherm, which is the extended Langmuir model:

$$
C_{p i}^{*}=\frac{q_{m i} \rho_{p} b_{i} C_{p i}}{1+\sum_{j=1}^{N_{s}} b_{j} C_{p j}}=\frac{\rho_{p} a_{i} C_{p i}}{1+\sum_{j=1}^{N_{s}} b_{j} C_{p j}}
$$

And in dimensionless form:

$$
c_{p i}^{*}=\frac{\rho_{p} a_{i} c_{p i}}{1+\sum_{j=1}^{N_{s}}\left(b_{j} C_{o j}\right) c_{p j}}
$$

Because of non-liner multi-component Langmuir isotherm is considered, finite elements method is used for the discretization of the bulk-fluid phase partial differential equation and the orthogonal collocation method for the particle phase equation is produced, The ordinary differential equation system with initial values can be readily solved using an ordinary differential equation solver such as the subroutine "ODE15S" of MATLAB V-7.3 which is a variable order solver based on the numerical differentiation formulas (NDFs)

\section{Experimental Materials and Procedure}

\begin{tabular}{|c|c|c|}
\hline Symbol & $\mathrm{ph}$ & $\mathrm{Pb}^{+2}$ \\
\hline Formula & $\mathrm{C}_{6} \mathrm{H}_{5} \mathrm{OH}$ & $\mathrm{Pb}\left(\mathrm{NO}_{3}\right)_{2}$ \\
\hline Structure & & $\ddot{N}_{-}^{+} \mid \mathrm{Pb}^{2+}$ \\
\hline Appearance & $\begin{array}{l}\text { White crystalline } \\
\text { solid }\end{array}$ & $\begin{array}{l}\text { White colorless } \\
\text { crystals }\end{array}$ \\
\hline Molecular weight, g/mole & 94.11 & 331.2 \\
\hline Solubility in water (at $\left.20^{\circ} \mathrm{C}\right), \mathrm{mg} / \mathrm{l}$ & 86000 & 520000 \\
\hline Octanal-Water, Log $\left(\mathrm{K}_{\mathrm{ow}}\right)$ & 1.5 & - \\
\hline Molar volume, $\mathrm{cm}^{3} / \mathrm{mole}$ & 93.7 & - \\
\hline Specific gravity & 1.058 & 4.53 \\
\hline Melting point, ${ }^{\circ} \mathrm{C}$ & 40.5 & 270 \\
\hline Boiling point, ${ }^{\circ} \mathrm{C}$ & 181.7 & - \\
\hline Molecular cross-sectional area, ${ }^{\circ} \mathrm{A}^{2}$ & 30.49 & 21.40 \\
\hline Manufacturing company & MERCK & MERCK \\
\hline
\end{tabular}

\section{Adsorbate}

$1000 \mathrm{mg} / \mathrm{l}$ standard stock solution of Phenol and lead (II) were prepared by dissolving $\mathrm{Ph}$ and $\mathrm{Pb}\left(\mathrm{NO}_{3}\right)_{2}$ in distilled water. The salts was bought from local market with the following specifications in Table 1.

Table 1: Main properties of phenol and lead nitrate [23].

\begin{tabular}{|l|l|}
\hline Property & GAC \\
\hline Actual density, $\mathrm{kg} / \mathrm{cm}^{3}$ & 1544 \\
\hline Apparent density, $\mathrm{kg} / \mathrm{cm}^{3}$ & 641 \\
\hline BET Surface area, $\mathrm{m}^{2} / \mathrm{g}$ & 751.965 \\
\hline Particle porosity & 0.584 \\
\hline Bed porosity & 0.64 \\
\hline Average particle diameter, $\mathrm{mm}$ & 0.775 \\
\hline Pore volume, $\mathrm{cm}^{3} / \mathrm{g}$ & 0.422 \\
\hline Average particle diameter, $\mathrm{mm}$ & $1100-1130$ \\
\hline pH & 8.15 \\
\hline lodine number, $\mathrm{mg} / \mathrm{g}$ & $3-5$ \\
\hline
\end{tabular}

Table 2: Physical and chemical properties of GAC.

\section{Adsorbent}

Commercial granulated activated carbon (GAC) was used as an adsorbent in the present work. It was supplied by (Unicarbo, Italians) and was bought from the Iraqi markets. The physical and chemical properties were measured at the laboratories of the Ministry of Industry and Minerals ( Ibn Sina State Company), Ministry of Oil (Petroleum Development and Research Center), Al-Mustansirria University (Collage of engineering, Environmental Department) and according to the data from the supplier. The physical and chemical properties of GAC are listed in Table 2.

\section{Procedure}

The initial $\mathrm{pH}$ of Phenol and lead solutions were measured by $\mathrm{pH}$ meter, (ORION 3 STAR, Thermo, US) and its found to be 5.45 and 4.40 respectively. The adsorption of metals and organics decrease at low $\mathrm{pH}$ values because of competition for binding sites between cations and protons, while at $\mathrm{pH}$ higher than 5.5, solubility of metal complexes decreases sufficiently allowing precipitation, which may complicate the sorption process and do not bind to the adsorption sites on the surface of the GAC. Therefore the optimum $\mathrm{pH}$ was found around $4[24,25]$. So, $\mathrm{pH}$ was adjusted with the range of (4) for all single and binary systems by adding the $0.1 \mathrm{~N} \mathrm{HNO}_{3}$ and $0.1 \mathrm{~N} \mathrm{NaOH}$ for acidic and basic $\mathrm{pH}$ respectively.

The fixed bed adsorber studies were designed and constructed of two acrylic columns of $(53 \mathrm{~mm})$ I.D. and $(0.5 \mathrm{~m})$ height. The granular activated carbon (GAC) bed is confined in the column by fine stainless steel screen at the bottom and a glass cylindrical packing at the top of the bed to ensure a uniform distribution of influent through the carbon bed. The influent solution is introduced to the column through a perforated plate, fixed at the top of the column.

For determination of the adsorption isotherm, a sample of (100 $\mathrm{ml})$ of each solution was placed in bottles of $(250 \mathrm{ml})$ in volume, containing $(0.05,0.1,0.15, \ldots$ to $0.6 \mathrm{~g})$ of GAC. The bottles were then placed on a shaker and agitated continuously at $250 \mathrm{rpm}$ for 24 hours at $30^{\circ} \mathrm{C}$ to achieve equilibrium concentrations. Then the solution was filtrated using filter paper type (Wattmann no. 4) and a sample of (20 $\mathrm{ml}$ ) from each bottles were taken for analysis to measure phenol and lead concentration respectively using (GC 1000, Italia) and (AAS, Buck,Accusys 211, USA). The adsorbed amount was calculated using the following equation [26]:

$$
q_{e}=\frac{V_{L}\left(C_{o}-C_{e}\right)}{W_{A}}
$$

The pore diffusion coefficient $\left(D_{\mathrm{p}}\right)$ for each solute was obtained by $2 \mathrm{~L}$ pyrex beaker fitted with variable speed mixer. The beaker was 
filled with $1 \mathrm{~L}$ of $50 \mathrm{mg} / \mathrm{l}$ concentration and the agitation started before the adding of GAC. At time zero, the accurate weight of GAC where added and samples were taken at specified time intervals. The necessary dosage of GAC, to reach equilibrium related concentration of $\mathrm{C}_{\mathrm{e}} / \mathrm{C}_{\mathrm{o}}$ equal to 0.05 , were calculated from Langmuir isotherm model and mass balance equation as follows:

$$
W_{A}=\frac{V_{L}\left(C_{o}-C_{e}\right)}{q_{e}}
$$

with

$$
q_{e}=\frac{q_{m} b C_{e}}{1+b C_{e}}
$$

\section{Results and Discussion}

\section{Adsorption isotherm}

The equilibrium isotherm for the investigated solutes $\left(\mathrm{Ph}\right.$ and $\left.\mathrm{Pb}^{+2}\right)$ onto GAC using multi-component Langmuir model are presented in Figure 1.The Langmuir model parameters $\left(\mathrm{q}_{\mathrm{m}}\right.$ and $\left.\mathrm{b}\right)$ were estimated by the non-linear regression method using STATISTICA version-6 soft ware The correlation coefficient $\left(\mathrm{R}^{2}\right)$ between the experimental data and the theoretical model is 0.9923 and 0.9963 for phenol and lead respectively. The Langmuir parameters are as follows:

- $\mathrm{Ph}: \mathrm{q}_{\mathrm{m}}=66.8234 \mathrm{mg} / \mathrm{g}, \mathrm{b}=0.0590 \mathrm{l} / \mathrm{mg}, \mathrm{R}^{2}=0.9923$

- $\mathrm{Pb}^{+2}: \mathrm{q}_{\mathrm{m}}=37.0370 \mathrm{mg} / \mathrm{g}, \mathrm{b}=0.1258 \mathrm{l} / \mathrm{mg}, \mathrm{R}^{2}=0.9963$

\section{Pore diffusion coefficient}

Pore diffusion coefficient $\left(\mathrm{D}_{\mathrm{p}}\right)$ of phenol and lead can be obtained using batch model by matching the concentration decay curve obtained from experimental data at optimum agitation speed $(400 \mathrm{rpm})$ with that obtained from the batch model as shown in Figure 2. At first time the pore diffusion coefficient is assumed and the model is solved numerically. This process continue until obtain perfect matching between the theoretical and experimental concentration decay curve. The principle parameter required for solving the batch model is the external mass transfer coefficient $\left(\mathrm{k}_{\mathrm{f}}\right)$ and the assumed pore diffusion coefficient $\left(D_{p}\right)$ the following steps must be made to introduce the

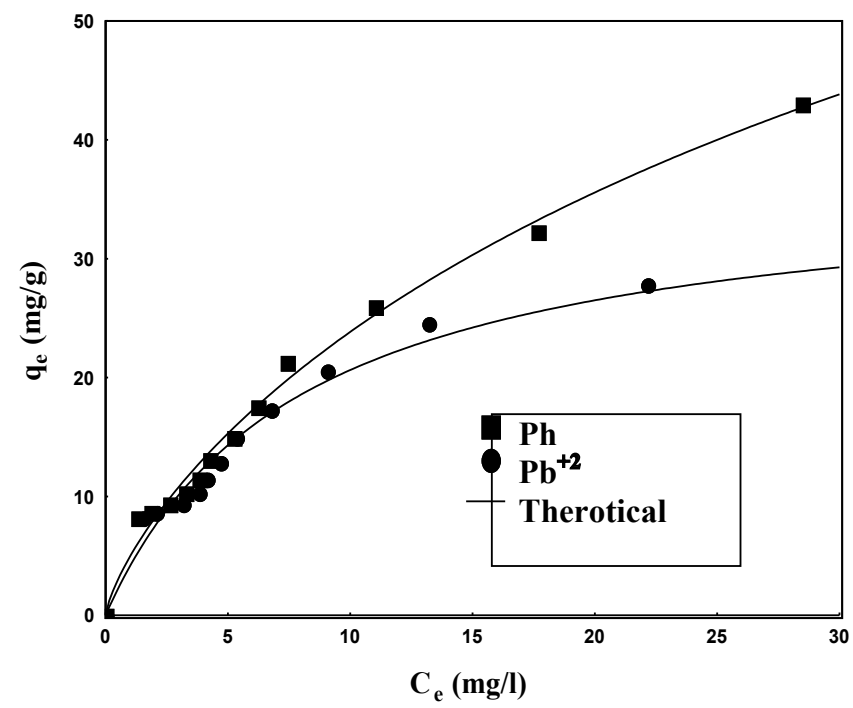

Figure 1: Adsorption isotherm for $\left(\mathrm{Ph}^{\left.-\mathrm{Pb}^{+2}\right)}\right.$ onto GAC.

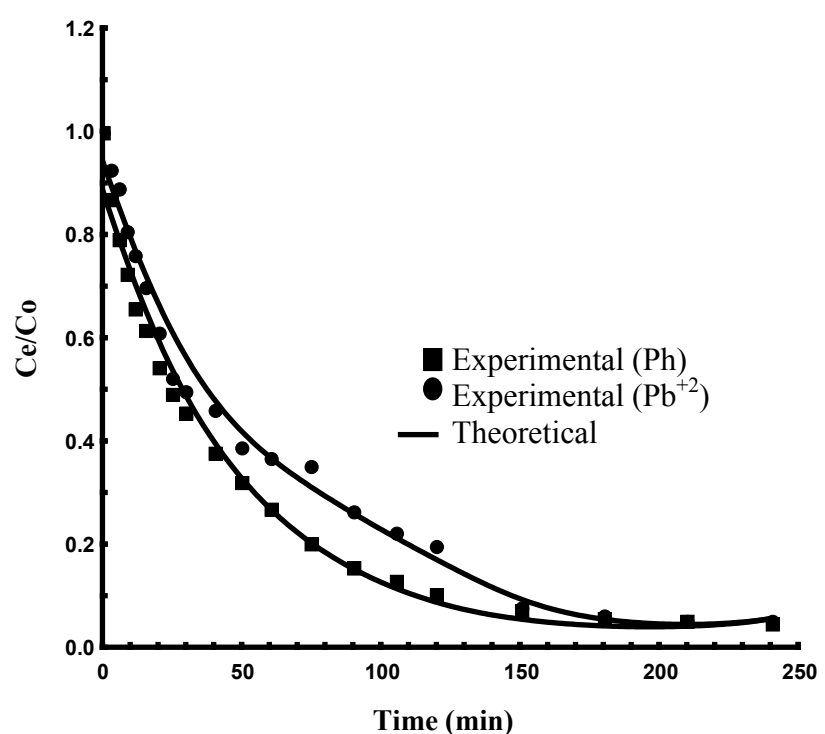

Figure 2: Comparison of the measured concentration-time decay data with that predicated by pore diffusion model for $\mathrm{Ph}$ and $\mathrm{Pb}^{+2}$.

required parameter conditions:

- Estimate the optimum concentration decay curve at optimum agitation speed.

- Numerical solution of the batch model can be used to obtain the theoretical concentration decay curve.

- Matching between the experimental and the theoretical concentration decay curve.

The pore diffusion coefficient for each solute are evaluated from batch experiments to be:

- $\mathrm{Ph}: \mathrm{D}_{\mathrm{p}}=5.523 \times 10^{-9} \mathrm{~m}^{2} / \mathrm{s}, \mathrm{R}^{2}=0.986$

- $\mathrm{Pb}^{+2}: \mathrm{D}_{\mathrm{p}}=3.143 \times 10^{-9} \mathrm{~m}^{2} / \mathrm{s}, \mathrm{R}^{2}=0.971$

The amount of GAC used for each solute were calculated from final equilibrium related concentration of $\mathrm{C}_{\mathrm{e}} / \mathrm{C}_{\mathrm{o}}=0.05$ using the Langmuir model with mass balance in $1 \mathrm{~L}$ of solution. The initial concentration were $50 \mathrm{mg} / \mathrm{l}$ with the doses of activated carbon of 5.530 and $5.360 \mathrm{~g}$ per $1 \mathrm{~L}$ solution for phenol and lead respectively. The external mass transfer coefficient , $\mathrm{k}_{\mathrm{f}}$ in fixed bed column model was calculated using the correlation of Crittenden (1987) [15].

$$
\mathrm{k}_{\mathrm{f}}=2.4 V_{\mathrm{s}} /\left(S c^{0.58} \mathrm{R}_{\mathrm{e}}^{0.66}\right)
$$

The liquid diffusivity coefficient was calculated using the equation:

$\mathrm{D}_{\mathrm{m}}=2.74^{\star} 10^{-9}(\mathrm{MW})-^{1 / 3}$

The axial dispersion coefficient $\mathrm{D}_{\mathrm{z}}$ of the liquid flowing through fixed beds was obtained from the following correlation [27]

$$
\frac{D_{z}}{D_{m}}=0.67+1.15\left[\frac{V_{s} d_{p}}{D_{m}}\right]^{1.2}
$$

\section{Breakthrough curves of the single and binary systems}

The experimental and predicated breakthrough curves for single and binary system for adsorption of phenol and lead onto GAC at different flow rate, bed height and initial concentration are shown in Figures 3 to 12 . 


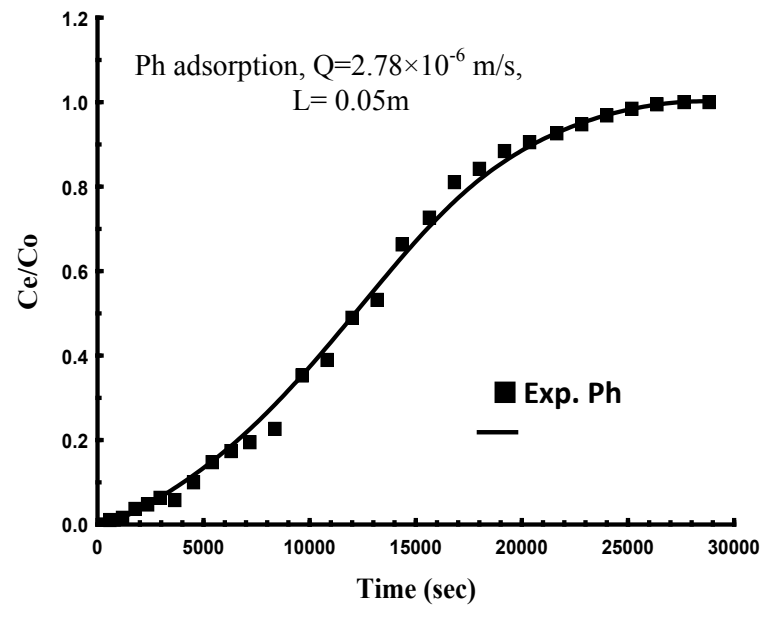

Figure 3: The experimental and predicated breakthrough curves for adsorption of single phenol onto GAC.

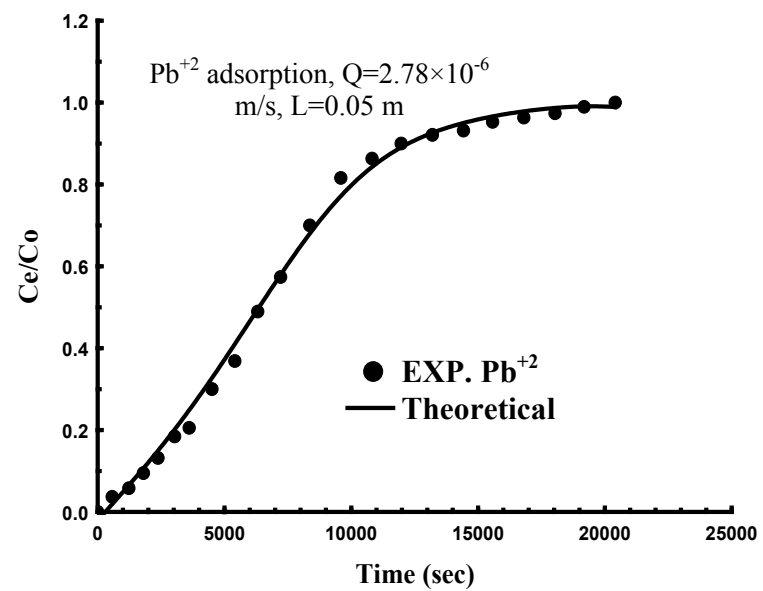

Figure 4: The experimental and predicated breakthrough curves for adsorption of single lead onto GAC.

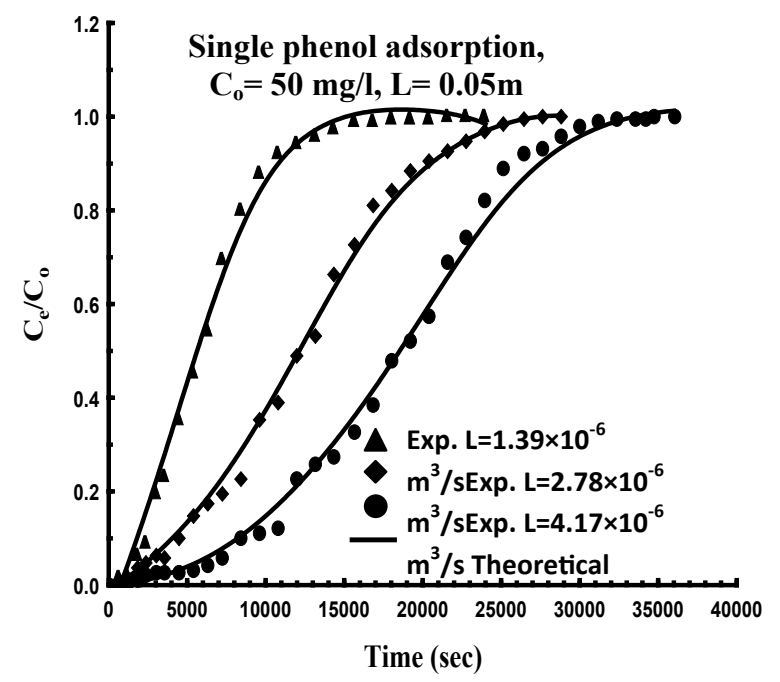

Figure 5: The experimental and predicated breakthrough curves for adsorption of single phenol onto GAC at different flow rate.

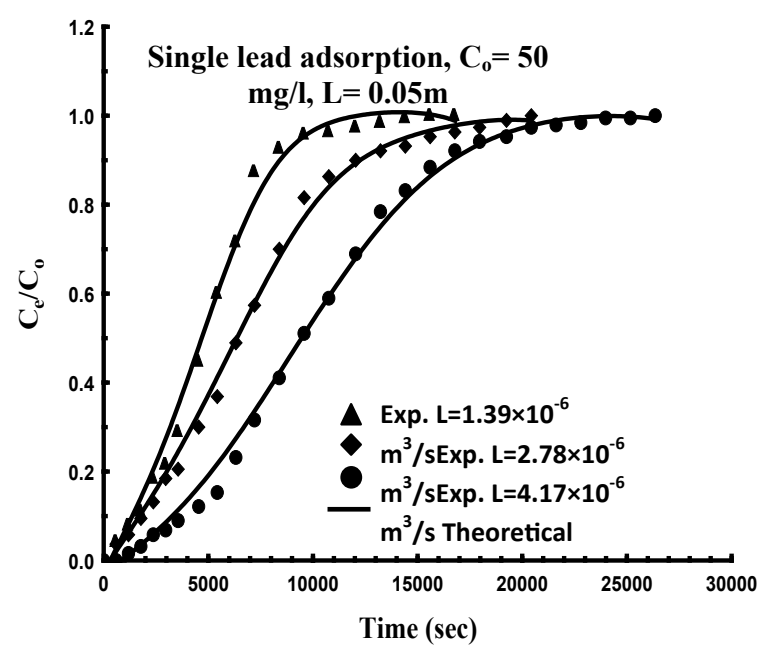

Figure 6: The experimental and predicated breakthrough curves for adsorption of single lead onto GAC at different flow rate.

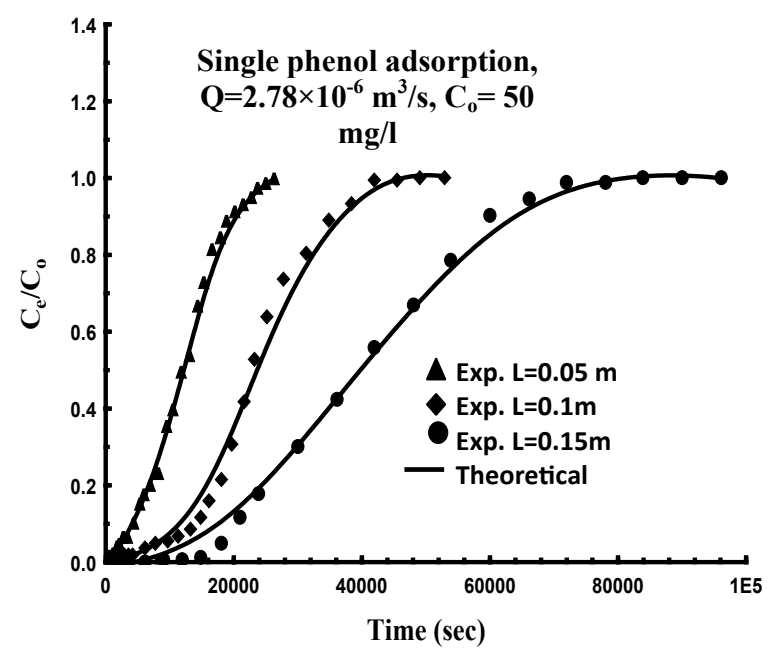

Figure 7: The experimental and predicated breakthrough curves for adsorption of single phenol onto GAC at different bed height.

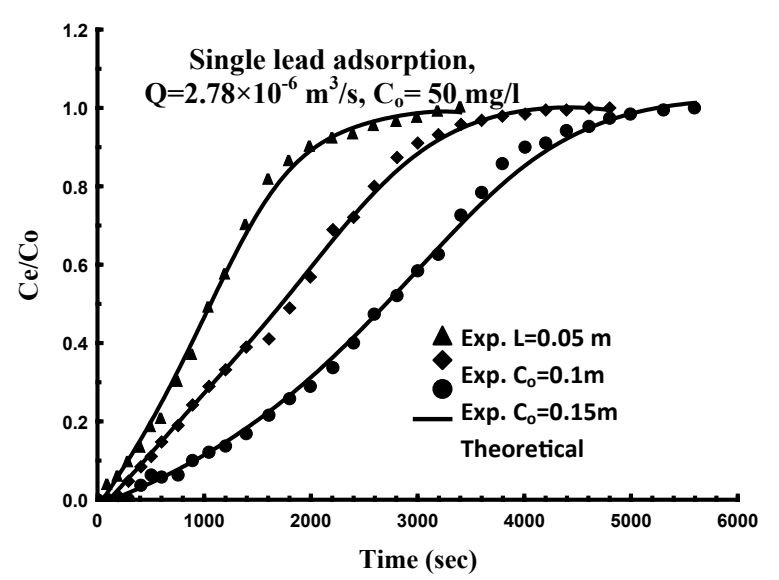

Figure 8: The experimental and predicated breakthrough curves for adsorption of single lead onto GAC at different bed height. 


\section{Discussion}

The adsorption capacity order for phenol and lead onto GAC was as follow

$\mathrm{Ph}(66.8234 \mathrm{mg} / \mathrm{g})>\mathrm{Pb}^{+2}(37.0370 \mathrm{mg} / \mathrm{g})$. This behavior of the capacity of the adsorbate in batch system seems to influence the adsorption capacity of GAC in fixed bed adsorber. This can be explained by

a- Phenol has less solubility $(86000 \mathrm{mg} / \mathrm{l})$ in water in comparison with lead nitrate $(520000 \mathrm{mg} / \mathrm{l})$ and consequently with lead.

b- Molecular cross-sectional area (molecular volume) for phenol is greater than lead $\left(21.40^{\circ} \mathrm{A}^{2}\right.$ for lead; $30.49^{\circ} \mathrm{A}^{2}$ for phenol).

c- Phenol can be adsorbed by means of electrostatic attraction between negatively charge phenols and positively charged binding sites. Physical adsorption by means of (Vander Waals, H-bonding, dipole-dipole and dipole-induced dipole) have been the main way to adsorb organics such as phenol. However, lead adsorption depended mainly only on the activity and availability of functional groups onto GAC (electrostatic

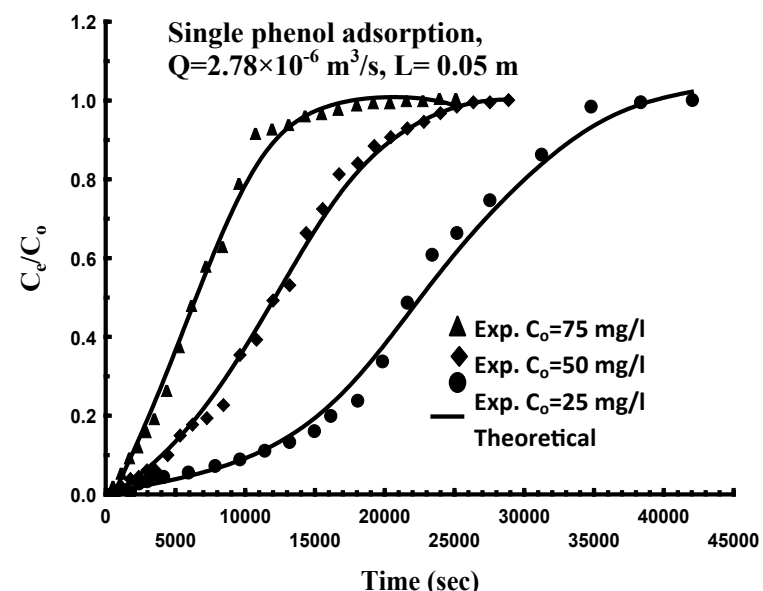

Figure 9: The experimental and predicated breakthrough curves for adsorption of single phenol onto GAC at different initial concentration.

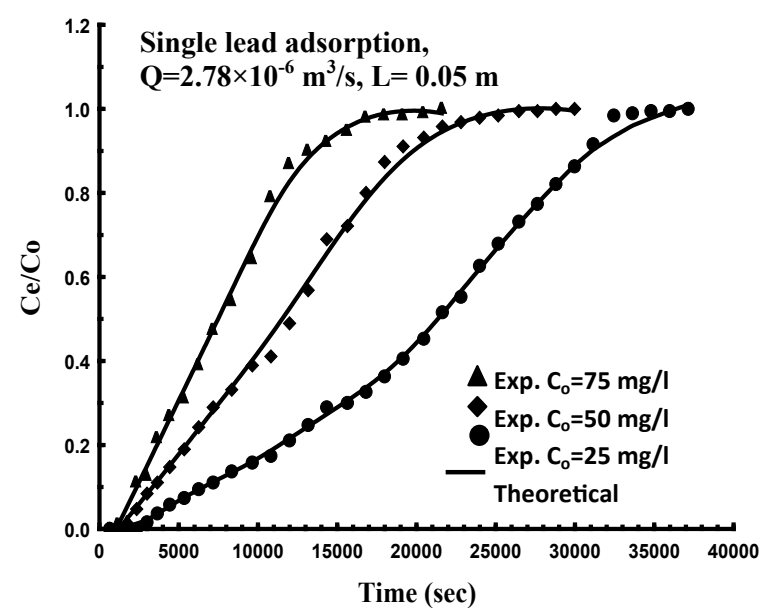

Figure 10: The experimental and predicated breakthrough curves for adsorption of single lead onto GAC at different initial concentration.

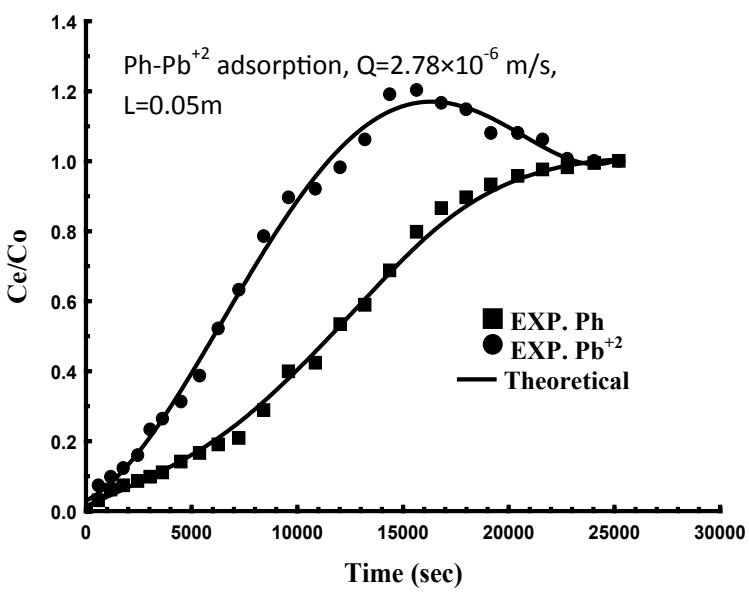

Figure 11: The experimental and predicated breakthrough curves for adsorption of binary $\mathrm{Ph}-\mathrm{Pb}^{+2}$ system onto GAC.

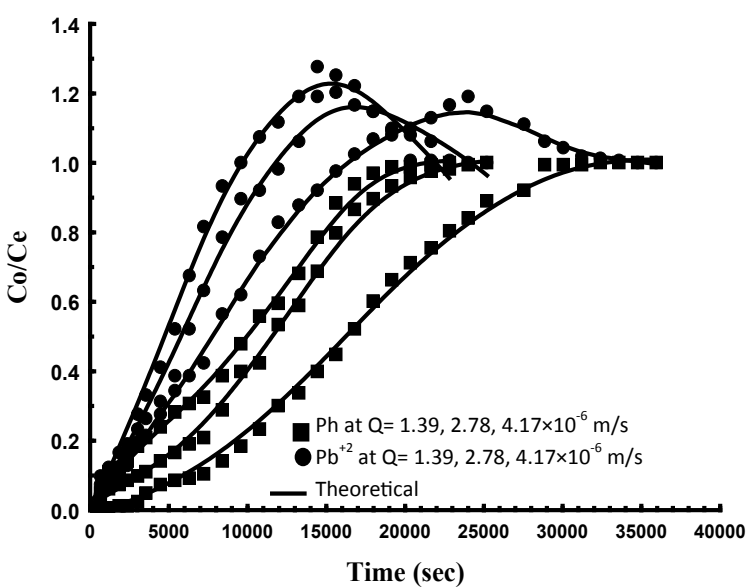

Figure 12: The experimental and predicated breakthrough curves for adsorption of $\mathrm{Ph}-\mathrm{Pb}^{+2}$ onto GAC at different flow rate.

attraction). This depend on type and treating of activated carbon with heat, acids or biases to increased these groups.

d- The binding of $\mathrm{Pb}^{+2}$ to GAC is based on the formation of coordination compounds. Lead ion acts as a Lewis acid and the GAC acts as a Lewis base. However, $\mathrm{Pb}^{+2}$ ion haven't enough electrons to reach an inert state, and to form Lewis acid-Lewis base neutralization process.

\section{Effect of flow rate}

Figures 5, 6 and 12 shows the experimental and predicated breakthrough curves for $\mathrm{Ph}$ and $\mathrm{Pb}^{+2}$ as a single and in binary systems at different flow rates $\left(1.39 \times 10^{-6}, 2.78 \times 10^{-6}\right.$ and $\left.4.17 \times 10^{-6} \mathrm{~m}^{3} / \mathrm{s}\right)$ in terms of $\mathrm{C}_{\mathrm{e}} / \mathrm{C}$.om these. It's clear from this figures that as the flow rate increases the time of breakthrough point decreases. This is because the residence time of solute in the bed decreases. Therefore there is no enough time for adsorption equilibrium to be reached which results in lower bed utilization and the adsorbate solution leaves the column before equilibrium .It is expected that the change in flow rate will effect the film diffusion but not the intra-particle diffusion. The higher the flow rates the smaller film resistance to mass transfer and hence larger $\mathrm{k}$ results. Increasing flow rate at constant bed height will increase the Biot 
Citation: Sulaymon AH, Abood DW, Ali AH (2011) Removal of Phenol and Lead from Synthetic Wastewater by Adsorption onto Granular Activated Carbon in Fixed Bed Adsorbers: predication of Breakthrough Curves. Hydrol Current Res 2:120. doi:10.4172/2157-7587.1000120

Page 7 of 5

number with slight increase in Peclet number as listed in Table 3. When the Biot number is high the time of breakthrough point will appear early. The higher Biot number values indicates that the film diffusion is not dominating compared to the intra-particle mass transfer and the intra-particle mass transfer is the controlling step. These results agree with those obtained by Sulaymoon and Ahmed [18]; Ebrahim [28]; Abdul-Hameed [29] and Nasir [30].

\section{Effects of bed height}

The bed height is one of the major parameter in the design of fixed bed adsorption column. The experimental and predicated breakthrough curves obtained for different bed height of activated carbon $(0.05,0.1$ and $0.15 \mathrm{~m})$ at constant flow rate and constant initial concentration are presented in Figures 7 and 8. It is clear from these figures that at smaller bed height the $\mathrm{C}_{e} / \mathrm{C}_{0}$ increase more rapidly than at higher bed height. Furthermore at smaller bed height the bed is saturated in less time compared with the higher bed height. Increasing the bed height at constant flow rate increases Peclet numbers as listed in Table 4. When Peclet number is small the effect of axial dispersion is not negligible, the break point appears early and increases with the Peclet number. Hence, the internal and external resistance are confirmed to be the main parameters that control the adsorption kinetics with the increase in bed height. It is clear that increasing bed height increases the breakthrough time and the residence time of the phenol and lead solution in the bed. Similar findings have been obtained by Sulymoon et al. [19].

\section{Effect of initial concentration}

The change in initial concentration of $\mathrm{Ph}$ and $\mathrm{Pb}^{+2}$ will have a significant effect on the breakthrough curves. Figures 9 and 10 shows the experimental and predicated breakthrough curves at different initial concentration $(25,50$ and $75 \mathrm{mg} / \mathrm{l})$. These figures shows that as the initial concentration increases the time of breakthrough point decreases. The higher the initial concentration, the faster the breakthrough curves; however, the activated carbon loadings are higher at higher initial concentration. For high initial concentration, steeper breakthrough curves are found because the equilibrium is attained faster.

\section{In multi-component system (binary system)}

For phenol and lead, it is clear from Figures 11 and 12 that, at the initial stage, there are a lot of active sites of GAC, and the strongly $(\mathrm{Ph})$ and weakly $\left(\mathrm{Pb}^{+2}\right)$ adsorbed component take the active site freely. With increasing time, the weakly adsorbed component is not easily adsorbed

\begin{tabular}{|l|l|l|l|}
\hline Pollutants & Flow rate, $\mathrm{m}^{3} / \mathrm{s}$ & Biot no. $(\mathrm{Bi})$ & Peclet no. $(\mathrm{Pe})$ \\
\hline \multirow{3}{*}{$\mathrm{Ph}$} & $1.39 \times 10^{-6}$ & 200.282 & 32.755 \\
\hline & $2.78 \times 10^{-6}$ & 258.6 & 33.521 \\
\hline \multirow{3}{*}{$\mathrm{Pb}^{+2}$} & $4.17 \times 10^{-6}$ & 303.190 & 33.955 \\
\hline & $1.39 \times 10^{-6}$ & 229.629 & 32.755 \\
\hline & $2.78 \times 10^{-6}$ & 296.370 & 33.521 \\
\hline & $4.17 \times 10^{-6}$ & 347.555 & 33.955 \\
\hline
\end{tabular}

Table 3: The values of Biot no. and Peclet no. at different flow rate.

\begin{tabular}{|l|l|l|l|}
\hline Pollutants & Bed height & Biot no. $(\mathrm{Bi})$ & Peclet no. $(\mathrm{Pe})$ \\
\hline \multirow{3}{*}{$\mathrm{Ph}$} & 0.05 & 258.6 & 31.206 \\
\hline & 0.10 & 258.6 & 62.412 \\
\hline \multirow{3}{*}{$\mathrm{Pb}^{+2}$} & 0.15 & 258.6 & 93.618 \\
\hline & 0.05 & 296.370 & 31.206 \\
\hline & 0.10 & 296.370 & 62.412 \\
\hline & 0.15 & 296.370 & 93.618 \\
\hline
\end{tabular}

Table 4: The values of Biot no. and Peclet no. at different bed height. but moves ahead with the bulk fluid and takes the active site first in the front part of the fixed bed. Because the strongly adsorbed component tends to take the active sites instead of the weakly adsorbed displace the sites that had been taken by the weakly adsorbed component. The result is that the local concentration of the weakly adsorbed component within the fixed bed adsorber is higher. These results are in agreement with that obtained by Ahmed [21] and Al-Najar [22].

\section{Conclusions}

1. The simulated breakthrough curves for adsorption of phenol and lead both in single and binary system onto granular activated carbon are in close agreement with the experimental results.Thus, the mathematical model, which includes axial dispersion, film mass transfer, pore diffusion resistance and nonlinear isotherm, provides a good description of the single and competitive adsorption process in fixed bed adsorbed.

2. Granular activated carbon was found to be more suitable adsorbent for the removal of organic pollutants (phenol in the present work) than inorganic pollutants (heavy metals, lead).

\section{References}

1. Patterson JW (1985) Industrial wastewater treatment technology. 53-393.

2. Chirwa EN, Wang YT (2000) Simultaneous chromium (VI) reduction and phenol degradation in an anaerobic consortium of bacteria.Water Res 34: 2376-2384.

3. Aksu Z, Akpinar D (2000) Modelling of simultaneous biosorption of pheno and nickel(II) onto dried aerobic activated sludge. Sep Purif Technol 21: 87-99.

4. Hassler JW (1974) Purification with Activated Carbon ; industrial, commercial, environmental. Chemical Publishing Co., New York.

5. Perrich JR (1981) Activated Carbon Adsorption for wastewater treatment. CRC Press, Boca Raton, FL

6. Callega G, Serna J, Rodriguez J (1993) Kinetics of adsorption of phenolic compounds from wastewater onto activated carbon. Carbon 31: 691-697.

7. Streat M, Patrick JW, Camporro MJP (1995) Sorption of phenol and parachlorophenol from water using conventional and novel activated carbons. Water Sci Res 29: 467-472.

8. Ferro-Garcia MA, Rivera-Utrilla J, Bautista-Toledo I, Moreno- Castilla C (1996) Chemical and thermal regeneration of an activated carbon saturated with chlorophenols. J Chem Technol Biotechnology 67: 83-189.

9. Lee JH, Song DI, Jeon WY (1997) Adsorption of organic phenojs onto dua organic cation montmorillonite from water. Sep Sci Technol 32:1975-1992.

10. Edgehill RU, Lu GQ (1998) Adsorption characteristics of carbonized bark for phenol and pentachlorophenol. J Chem Technol Biotechnol 71: 27-34.

11. Aksu Z, Gonen F (2005) Binary biosorption of phenol and chromium (VI) onto immobilized activated sludge in a packed bed: Prediction of kinetic parameters and breakthrough curves. Sep Purif Technol 49: 205-216.

12. ATSDR. Agency for Toxic Substances and Disease Registry, Toxicologica Profile for dichlorophenol, Atlanta, Georgia :US Department of Health and Human Services, DHHS. Publication, No.TP-91/14,1992.

13. Aksu Z, Gonen F (2005) Binary biosorption of phenol and chromium (VI) onto immobilized activated sludge in a packed bed: Prediction of kinetic parameters and breakthrough curves. Sep Purify Technol 49: 205-216.

14. Esposito A, Pagnanelli $F$, Vegliò $F$ (2002) pH-related equilibria models for biosorption in single metal systems. Chem Eng Sci 57: 307-313.

15. Crittenden JC, Thomas FS, David WH, Paul JL, Ben L (1987) Evaluating Multicomponent Competitive Adsorption in Fixed-Beds. J. Environ Eng 113: 1363 1375 .

16. Bhatia SC (2005) Environmental pollution and control in Chemical process Industries. Khana publisher 250-260.

17. Volesky B, Prasetyo I (1994) Cadmium removal in a biosorption column Biotechnol Bioeng 43: 1010-1015. 
Citation: Sulaymon AH, Abood DW, Ali AH (2011) Removal of Phenol and Lead from Synthetic Wastewater by Adsorption onto Granular Activated Carbon in Fixed Bed Adsorbers: predication of Breakthrough Curves. Hydrol Current Res 2:120. doi:10.4172/2157-7587.1000120

Page 8 of 5

18. Sulaymon AH, Ahmed KW (2008) Competitive adsorption of Furfural and Phenolic Compounds onto Activated Carbon in Fixed Bed Column. J Environ Sci Technol 42: 392-397.

19. Sulaymon AH, Abid BA, Al-Najar JA (2009) Removal of lead copper chromium and cobalt ions onto granular activated carbon in batch and fixed bed adsorbers, Chem Eng Journal 155: 647-653.

20. Eggers SL, Eggers R (2000) Simulation of Frontal Adsorption, HIWI report by Hamburg-Harburg University.

21. Ahmed KW (2006) Removal of multi-pollutants from wastewater by adsorption method. Ph.D. Thesis, University of Baghdad.

22. Al-Najar JA (2009) Removal of heavy metals by adsorption using activated carbon and Kaolinte. Ph.D Thesis, University of Technology, Baghdad, Baghdad, Iraq.

23. Temkin M (1934) Die gas adsorption und der nernstsche wärmesatz. Acta Physicochim URSS 1: 36-52.

24. Weber WJ (1972) Adsorption In: Physicochemical processes for water quality control. New York, Wiley 206-211.

25. Garden AJ (2006) Application of Harkins Model in Adsorption. IAH J 7: 11-14

26. Redlich O, Peterson DL (1959) A useful adsorption isotherm. J Phys Chem 63: 1024.

27. Hutzler NJ, Crittenden JC, Gierke JS, Johnson AS (1986) Transport of organic compounds with saturated ground water flow : experimental results. Wat Res Research 22: 285-295.

28. Ebrahim ShE (2008) Competitive Adsorption of Multi-Organic Compounds onto Organoclay from Simulated Wastewater. Ph.D. Thesis, University of Baghdad College of Engineering

29. Abdul-Hameed HM (2009) Competitive adsorption of heavy metals onto activated carbon in fixed bed column. Ph.D. Thesis ,University of Baghdad, College of Engineering.

30. Nasir HM (2010) Competitive Adsorption of Multi-Organic Compounds onto Organoclay from Simulated Wastewater. Ph.D. Thesis, University of Baghdad, College of Engineering 